\title{
Tourist Expectations Toward Travel And Tourism Websites In Thailand
}

\author{
Kemakorn Chaiprasit, Chiang Mai University, Thailand \\ Nittaya Jariangprasert, Chiang Mai University, Thailand \\ Apichart Chomphunut, Chiang Mai University, Thailand \\ Damrongsak Naparat, Chiang Mai University, Thailand \\ Jairat Jaturapataraporn, Small Business Counselor, Thailand
}

\begin{abstract}
As there is still only limited research about expectations and preferences of travel and tourism websites, the aim of the paper is to enhance this body of knowledge by providing theoretical and empirical evidences about tourists' expectations and preferences toward the roles of functionality/usability factors and quality of information of Thai travel tourism websites. A total 415 tourists were investigated by a structured questionnaire. The empirical findings indicated that 1) there was significant difference of tourists' expectation between functionality/usability factors and quality of information of travel tourism websites at statistic level of 0.05. 2) tourists had expectation and preference on quality of information factor higher than functionality/usability factors 3) the three attributes most expected for functionality/usability factors were ease of physical access to the website, less response time, and easy access to specific detail within the website 4) the three attributes most expected for quality of information were current reliable information, useful sufficient information about tourism products/services and travel facilities including detailed and comprehensive coverage of travel tourism information.
\end{abstract}

Keywords: E-tourism; Thailand E-tourism; Tourism Websites Expectation

\section{BACKGROUND AND RATIONALE}

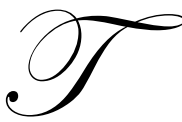

ourism has become one of the fastest growing sectors of the global economy. Globally including Thailand, tourism generates income and employment thus it is regarded as one of the most dynamic devices in the country's economic development. In realizing the importance of tourism industry which is experiencing prosperity, the Royal Thai Government, Ministry of Tourism and Sports, Tourism Authority of Thailand as well as local private and public agencies all participate in tourism both policy and practice. From the study of Retained Value of the Tourism Industry of Thailand (Social Research Institute, Chiang Mai University, 2004) found the top three benefits of tourism promotion policies were 1) to enhance country reputation 2) to instill pride in the nation and 3) to become the source of foreign currency. According to Tourism 2020 Vision by World Tourism Organization forecasted that East Asia and the Pacific tourism growth rate will be over 6.5 per cent in 2020. For tourism business, the Internet offers the potential to make information and booking facilities available to large number of tourists at relatively low costs. It also provides a tool for communication between tourism suppliers, intermediaries, as well as end-consumers. Internet facilitates tourists to access to information easily and instantly then encourages purchase desire and decision. Internet also reduces business costs so it changes traditional pricing structures and offers alternative lower pricings that maximize more sales. Web applications enable a personalized travel package that tourists become center of tourism planning as a result tourism products/services/pricing are more flexible than fixed or so called customer-oriented or customization (Werthner \& Ricci, 2004).

Internet becomes the most influential innovation toward tourism and travel businesses. Governments both in developed and developing countries together with tourism and travel related organizations including World Tourism Organization (WTO), United Nations Conference on Trade and Development (UNCTAD), Organization for Economic Co-operation and Development (OECD) all participate in supporting tourism enterprises especially 
the small and medium enterprises (SMEs) to utilize the benefits of Internet and ICTs for the most of their tourism potential in order to maximize their competitiveness and competitive advantages. In developing from tourism to Etourism and in utilizing the Internet marketing, website is the most important tool. Since the Internet has allowed businesses to break through the geographic barriers and become accessible by potential customers. Website is a medium for representation of company also a form of media from which everybody can acquire information. Company can use website to create online community that exchanges information and opinions anywhere anytime. Hence, company can only sells online through website that most satisfies customers. Though e-tourism has been a growing trend, tourism actors such as travel agencies, tour operators, booking agents, etc. widely adopted e-tourism but they are more likely fail than succeed with several reasons. However, having a great websites are not good enough. Tourism enterprises also have to work on promoting their website to get noticed by visitors and to get enough targeted traffic visits to make websites profitable. Without a doubt, one major failure reason is that Etourism websites owners do not take into serious account in marketing and maintaining after making the websites (Siripullop, 2006).

After investigation both travel tourism websites designs and developments including web users' behaviors, various studies obviously show that E-tourism play important roles in tourism promotion. In the context of travel and tourism, the information intensive and customer oriented are the nature of the industry so websites appear to be the strategic tools to deliver information, business transactions, and relation building with customers. To ensure the best possible outcome that websites contributing to the achievement of tourism enterprises, tourists' expectations and preferences toward travel tourism websites are needed. The preliminary study found that Thai travel tourism related websites especially government websites did not aware the importance of functionality, usability or quality of information so those websites often fail to satisfy and attract more visitors either to maximize the returns when promoting Thai tourism products and services through E-tourism channel.

Travel and tourism researches, however, have rarely investigated the expectation of tourists toward travel tourism websites especially in Thailand. This study aims to provide a better understanding of tourists' expectations and preferences toward functionality and usability factors as well as quality of information factors of the website. The results of this study will be beneficial for travel and tourism businesses that seek competitive advantages and success in E-tourism. Meanwhile this also can be a venerable roadmap for Thai government and supporting divisions in promoting Thai E-tourism in the near future.

\section{REVIEW OF RELATED LITERATURES AND CONCEPTUAL FRAMEWORK}

Tourism is by nature the information-incentive industry. Therefore it is mostly needed to understand online tourists' behaviors and purchase patterns in order to design and develop the effective website. Findings from related researches and studies are as following:

1) Study of the Influence of the Internet on Destination Satisfaction found that the greater the tourist's satisfaction with the Internet, the fuller was his or her enjoyment of the holiday. This relationship, however, was moderated by two variables - the tourist's previous experience of the destination and the tourist's experience of the Internet. These conclusions may well prove crucial for the future use of the Internet in the promotion of tourism destinations (Castaneda, Frias, \& Rodriguez, 2007).

2) Survey of Global Online Travel Consumers in May 2009 shown that consumers were still primarily influenced by price when deciding on a holiday/vacation also had additional information needs that change at each stage of the booking cycle. The survey also showed that consumers were frustrated by out-of-date information, hidden fees and misleading descriptions, as well as technology-related issues such as slow downloads and broken links (E-Digital Research, 2009).

3) Study of Trust and New Technologies: Looking at Issues from the Perspective of the Young Tourists shown that while the Internet was the primary source of data, the information collection and many New Technologies were used in this process, decision making was still driven by more personal and neutral traditional sources of information such as recommendations from friends, relatives and colleagues, travel guide books and travel agents (Henderson, Slaughter, \& Pegg, 2007). 
4) Study of E-Tourism in African Developing Countries shown that E-tourism was widely adopted by African travel and tourism providers yet most of the websites still lacked of useful and sufficient information even with poor search tool. This somewhat gave negative effect against the brand identity of the country (Lai \& Fei Loi, 2007).

5) Study of E-Commerce and Tourism suggested that the website was used not only for information gathering, but also for ordering services as well as building a personalized travel package so a successful website should therefore be easy to access, find basic information, search more details, purchase and take customers' interest (Werthner \& Ricci, 2004).

6) Study of Planning of Internet Marketing Strategy for Wing Travel Chiang Mai Co., Ltd. found that Korean tourists preferred searching information online through search engines about Thai tourism products and services but actually bought through travel agents (Khumsri, 2006).

7) Study of Lifestyle, Information Seeking for Travelling and Travel Behavior of Working People segmented lifestyle of working people into 9 groups; competition-loving, next generation, conservative, up-to-date, nouveau leadership, family-oriented, self-indulgent, trend follower, and independent group. Working people with different age, education, and marriage status had significantly different travel behaviors. In addition, the use of information seeking, psychographic, and demographic variables all together could explain travel behavior better than the use of information seeking and psychographic variables (Kerdmongkol, 2003).

8) Study of Factors Affecting Trust Towards Information Services Offered on the World Wide Web found that the sampled users used the services of online academic journals, research and online merchandise ordering because of ease of usage rather than the trustworthiness of the services. As for the chat room services, the sampled users were most interested in the entertainment factor. In regard to problems in usage, system delay and failure were identified as the foremost problems in seeking academic and research information and ordering merchandise online (Kunakornvaroj, 2001).

9) Study of Marketing Publications Strategies on Internet for Event Organizing studied the patterns, contents, marketing and public relations strategies of the six websites promoting events organizing on Internet. The results found that entertainment websites needed presentation of content, message, picture, sound, effect and picture animation including interpersonal communication (Eaimrittikrai, 2001).

The above significant findings led to questions regarding expectations and preferences of the tourists having experiences on Thai travel tourism websites in order to design and develop the effective E-tourism websites.

\section{Functionality and Usability of Travel and Tourism Website}

Questions regarding expectations and preferences toward the functionality and usability of travel and tourism websites, there were 11 questions as following: 1) Ease of physical access to the website 2) Less response time 3) Help and orientation 4) Language 5) Privacy and security 6) Easy access to specific detail within the website 7) Ability to access information in multiple ways and from various points in the system 8) Prompt and helpful response to customer 9) Online reservation 10) Online community 11) Advanced functionality

\section{Quality of Information of Travel and Tourism Websites}

Questions regarding expectations and preferences toward the quality of information in the website, there were 8 questions as following: 1) Contact information 2) Product/service and facility information 3) Purchase information 4) Comprehensive coverage 5) Current and reliable information 6) Other Information 7) Hyperlinks to relevant websites 8) Aesthetic design and appealing

\section{METHODOLOGY}

The survey aimed to exploring tourist expectations and preferences toward travel and tourism websites in Thailand. Base on functionality and usability of the website, and quality of information, a structured questionnaire was developed. The questionnaire consisted of three sections. The first section, 19 questions, was about to investigate expectations and preferences of tourists toward Thai travel tourism websites (11 questions asked about functionality and usability and 8 questions asked about quality of information). The respondents were requested to state their 
expectations in each question on a five-point Likert scale. The second section, 2 questions, was about the website usage behavior asked about the top three travel tourism websites that respondents most frequently visited as well as the online purchase of Thai travel tourism products/services within the past 12 months. The third section, 5 questions, was about personal information asked for demographic variables including frequency of Internet use, gender, age, education and country/region of residence.

Since the questionnaire was used to investigate both Thai and foreign tourists, the original Thai questionnaire was translated into English with a back-translation to ensure that both questionnaires had the same meaning. For content validity and comprehensiveness, the questionnaire was tested by the expert then pilot tested with 20 tourists. Some minor adjustments were made in response to the comments received from expert and the participants. The survey was conducted during October to December 2009 both web-based questionnaire and faceto-face interviews in Chiang Mai, Thailand. At the end, 415 tourists responded. 250 of them were Thai and 165 were foreign. The data collected from 415 respondents were analyzed using descriptive statistics. In addition, independent sample t-tests were used to identify the differences between demographic data and tourists expectations.

\section{RESULTS}

Among the respondents who visited at least one Thai travel tourism website (Table 1), the numbers of male and female respondents were $40.7 \%$ and $58.8 \%$. The largest group of these travel tourism websites users was aged 21-30, graduated at bachelor level. There were $60.2 \%$ of Thai tourists and $39.8 \%$ of foreign tourists. Most of Thai tourists resided in the northern part of Thailand while the largest group of foreign tourists came from Asia.

Table 1: Demographic profile of the respondents

\begin{tabular}{|l|c|c|}
\hline Variable & $\mathbf{n}$ & \% \\
\hline Gender $(\mathrm{n}=415)$ & & 40.7 \\
\hline Male & 169 & 58.8 \\
\hline Female & 244 & 0.5 \\
\hline Others & 2 & \\
\hline & & \\
\hline Age $(\mathrm{n}=415)$ & & 10.1 \\
\hline Under 0 & 42 & 64.3 \\
\hline $21-30$ & 267 & 13.5 \\
\hline $31-40$ & 56 & 12.0 \\
\hline Above 40 & 50 & \\
\hline
\end{tabular}

\begin{tabular}{|l|c|c|}
\hline Education $(\mathrm{n}=415)$ & 72 & 17.3 \\
\hline Less than bachelor & 195 & 47.0 \\
\hline Completed bachelor & 148 & 35.7 \\
\hline Above bachelor & & \\
\hline & & \\
\hline Region of residence of Thai tourists $(\mathrm{n}=250)$ & 46 & 18.4 \\
\hline Bangkok & 193 & 1.6 \\
\hline Northern & 4 & 1.6 \\
\hline Middle & 4 & 1.2 \\
\hline Eastern & 3 & \\
\hline Western & & \\
\hline & & \\
\hline Region of residence offoreign tourists $(\mathrm{n}=165)$ & 58 & 35.2 \\
\hline Asia & 48 & 29.1 \\
\hline North America & 1 & 0.6 \\
\hline South America & 51 & 30.9 \\
\hline Europe & 7 & 4.2 \\
\hline Australia & & \\
\hline
\end{tabular}




\section{Travel Tourism Website Using Behavior}

Most of respondents visited travel tourism websites everyday at $46.3 \%$ and visited once a week at $36 \%$. Among respondents, $55.7 \%$ purchased online immediately whereas $44.3 \%$ did not.

Table 2: Travel website using behavior

\begin{tabular}{|l|c|c|}
\hline \multicolumn{1}{|c|}{ Variable } & $\mathbf{n}$ & \% \\
\hline Frequency of website visited $(\mathrm{n}=415)$ & & 46.3 \\
\hline Everyday & 192 & 36.4 \\
\hline Once a week & 151 & 6.0 \\
\hline Once a month & 25 & 11.3 \\
\hline Seldom & 47 & \\
\hline Decision making $(\mathrm{n}=415)$ & & 55.7 \\
\hline Immediately & 231 & 44.3 \\
\hline Not immediately & 184 & \\
\hline
\end{tabular}

Table 3: Expectations and preferences for travel tourism websites

\begin{tabular}{|c|c|c|c|}
\hline $\begin{array}{ll} & \text { Variable } \\
\end{array}$ & Mean & SD & Ranking \\
\hline \multicolumn{4}{|l|}{ Functionality and Usability Factors } \\
\hline Ease of physical access to the website & 4.19 & 0.72 & 1 \\
\hline Less response time & 4.01 & 0.84 & 2 \\
\hline Provides both help and orientation & 3.69 & 0.87 & 11 \\
\hline Language & 3.92 & 0.90 & 4 \\
\hline Security \& privacy & 3.78 & 1.02 & 7 \\
\hline Easy access to specific detail within the website & 3.96 & 0.82 & 3 \\
\hline $\begin{array}{l}\text { Ability to access information in multiple ways and from various points in the } \\
\text { systems }\end{array}$ & 3.72 & 0.88 & 10 \\
\hline Prompt and helpful response to customers & 3.79 & 0.87 & 5 \\
\hline Online reservation & 3.78 & 0.87 & 7 \\
\hline Online community & 3.79 & 0.88 & 5 \\
\hline Advanced functionality, e.g. multimedia, photo gallery, VDO clip & 3.76 & 0.90 & 9 \\
\hline Total & 3.85 & 0.54 & \\
\hline \multicolumn{4}{|l|}{ Quality of Information factors } \\
\hline Contact information & 3.93 & 0.72 & 7 \\
\hline Service/products \& facility information & 4.19 & 0.84 & 2 \\
\hline Purchase information & 3.98 & 0.87 & 4 \\
\hline Comprehensive coverage & 4.09 & 0.90 & 3 \\
\hline Current and reliable information & 4.21 & 1.02 & 1 \\
\hline $\begin{array}{l}\text { Other information e.g. promotion, award system, passport \& visa, guided tour, } \\
\text { rating \& award winning, social \& culture, exchange rate }\end{array}$ & 3.93 & 0.82 & 6 \\
\hline Hyperlinks to relevant websites & 3.91 & 0.88 & 8 \\
\hline Aesthetics design \& appealing & 3.95 & 0.87 & 5 \\
\hline Total & 4.02 & 0.58 & \\
\hline
\end{tabular}

\section{Expectations toward Functionality and Usability of Travel Tourism Websites}

Table 3 shows the expectations and preferences of tourists on the eleven attributes of functionality and usability factors. Functionality and usability of travel tourism websites were expected at high level with mean values 3.85. The most three expectations were easy of physical access to the website (mean=4.19), less response time (mean=4.01), and easy access to specific detail within the website (mean=3.96). 


\section{Expectations toward Quality of Information of Travel Tourism Websites}

In addition, Table 3, eight attributes of the quality of information factors of travel tourism websites were expected at high level with mean values 4.02. The most three expectations were current and reliable information (mean=4.21), service/products and facility information (mean=4.19), and comprehensive coverage (mean=4.09).

Among eleven attributes of functionality and usability factors as well as eight attributes of quality of information factor, there was significant difference of tourists' expectations and preferences at statistic level of 0.05 . (Table 4)

Table 4: Difference of expectations and preferences

\begin{tabular}{|l|c|c|c|c|c|}
\hline \multicolumn{1}{|c|}{ Variable } & n & Mean & SD & t value & Sig \\
\hline Functionality and usability & 415 & 3.85 & 0.536 & \multirow{2}{*}{-4.406} & $0.000 *$ \\
\hline Quality of information & 415 & 4.02 & 0.575 & & \\
\end{tabular}

\section{Relationships between Demographics and Tourists Expectations}

The relationships between demographics and tourists expectations toward travel tourism websites were presented in t-test value. (Table 5)

Table 5: Relationships between demographics and tourists expectations

\begin{tabular}{|c|c|c|c|c|c|}
\hline Variable & Gender & Nationality & Age & Education & $\begin{array}{l}\text { Decision } \\
\text { Making }\end{array}$ \\
\hline \multicolumn{6}{|l|}{ Functionality and Usability Factors } \\
\hline Ease of access to the website & - & $\star$ & $\star$ & $\star$ & - \\
\hline Less response time & $\star$ & - & - & $\star$ & - \\
\hline Help and orientation & - & - & - & - & $\star$ \\
\hline Language & - & - & - & - & $\star$ \\
\hline \multicolumn{6}{|l|}{ Security and privacy } \\
\hline Easy access to specific detail within the website & - & - & - & - & $\star$ \\
\hline $\begin{array}{l}\text { Ability to access information in multiple ways and } \\
\text { from various points in the systems }\end{array}$ & $\star$ & $\star$ & - & $\star$ & - \\
\hline \multicolumn{6}{|l|}{ Prompt helpful response to customers } \\
\hline Online reservation & $\star$ & - & - & - & $\star$ \\
\hline Online community & - & $\star$ & - & - & - \\
\hline $\begin{array}{l}\text { Advanced functionality, e.g. multimedia, photo } \\
\text { gallery, VDO clip }\end{array}$ & $\star$ & $\star$ & - & - & - \\
\hline \multicolumn{6}{|l|}{ Quality of information factors } \\
\hline \multicolumn{6}{|l|}{ Contact information } \\
\hline Service/products/facility information & $\star$ & - & $\star$ & - & $\star$ \\
\hline Purchase information & - & - & - & - & $\star$ \\
\hline Comprehensive coverage & - & - & - & - & $\star$ \\
\hline Current reliable information & - & - & - & - & $\star$ \\
\hline $\begin{array}{l}\text { Other information e.g. promotion, award system, } \\
\text { passport \& visa, guided tour, rating \& award } \\
\text { winning, social \& culture, exchange rate }\end{array}$ & $\star$ & - & - & - & $\star$ \\
\hline Hyperlinks to relevant websites & $\star$ & $\star$ & $\star$ & - & - \\
\hline Aesthetics design \& appealing & $\star$ & $\star$ & $\star$ & - & - \\
\hline
\end{tabular}

Remark:

Gender $=$ male/female, Nationality $=$ Thai/foreign, Age $=$ young $($ under 30)/working age $($ above 30$)$, Education $=$ less than bachelor/completed and above bachelor, Decision Making = immediately/not immediately

$\star$ Differences at statistic level of 0.05 


\section{CONCLUSIONS}

The sample of 415 tourists in this study expected and preferred on quality of information in travel tourism websites higher than functionality and usability of the websites. The most three expected and preferred attributes of functionality and usability of travel tourism websites were the ease of physical access to the website, less response time, and easy access to specific detail within the website. The most three expected and preferred attributes of quality of information factor of travel tourism websites were the current reliable information, useful sufficient information about tourism products/services and travel facilities including detailed and comprehensive coverage of travel tourism information.

\section{RECOMMENDATIONS ON DESIGN AND DEVELOPMENT OF TRAVEL TOURISM WEBSITES}

In designing and developing a website to be the most effective and cost effective marketing tool, three phases should be considered. There are (1) Phase of making the website. Website is the company online presence. To look professional and to build trust with visitors through company website, the company makes certain on quality as well as the ability of the website to best serve company's target audience. (2) Phase of marketing the website. Website must be seen and reached by company target audience, this phase the company puts effort on promoting and attracting visitors to the website. (3) Phase of maintaining the website. This phase is just as important as making the website in the first place. To draw new visitors and retain existing customers, company must keep the content fresh with competitive commerce and convenience against company competitor. It is long term commitment, maintaining the website is never done.

Since this study focuses only the phase of making the website, especially travel tourism websites, the following recommendations may be useful for travel tourism entrepreneurs to consider when planning for E-tourism website:

1. Designing the website. It begins with identifying and analyzing the target audience so the company understands requirements, expectations, preferences, and behaviors of website visitors who in this study mean online tourists. Audience analysis allows company to decide for functionality and usability as well as information needed in the website, so called user-centered design. Company can precisely decide which language or multi-language including other functions and services to be presented in the website. In summary, designing the website should consider over content, convenience, commerce, communication, customization and/or community concepts. The result of this study shows different requirements, expectations, preferences, and behaviors of tourists at different backgrounds of gender, age, education and nationality. For example Thai tourists highly expect on aesthetic design and appealing of travel tourism websites higher than foreign tourists while female tourists highly expect on necessary detailed information especially promotional information higher than male tourists.

2. Developing the website. The precise website designing leads to professional website developing. Developing website begins with content and structure then adds in aesthetic graphics to make the website appealing to target audience. However the website must be simple to navigate, clear, layered, organized, user-friendly, speedy response, secure, reliable, after all easy efficient to use. The 'KISS' model (Keep It $\underline{\text { Super }} \underline{\text { Simple or }} \underline{\text { Simple }} \underline{\text { Stupid, for }}$ website audience) is good approach for website development.

3. Functionality and usability of the website. According to the result of this study, tourists expect and prefer that travel tourism websites comprise with the following functionality and usability:

- $\quad$ Ease of physical access to the website

- $\quad$ Ease of access to specific detail within the website

- $\quad$ Less response time

- $\quad$ Language, at least available in English and local language or further provide multi-language feature support

4. Quality of Information of the website. According to the result of this study, tourists expect and prefer that travel tourism websites provide current, reliable, useful and sufficient for following information: 
- $\quad$ Service/product information of the website, tourists expect complete information about tourism products, services, travel facility that website offers to sell or serve i.e. package tours, accommodations, things to do, leisure activities, etc.

- Purchase information, tourists expect complete information that tourists can view or edit about their reservation, purchase, payment confirmation, and/or special requirements.

- $\quad$ Comprehensive coverage, tourists expect more about travel tourism information related to service/product that tourists purchase from the website, for example travel guide, advice, tips and destination information. The comprehensive coverage help tourists better plan their trip. Referring to the previous study shows that the greater the tourists' satisfaction with information from the website, the fuller is enjoyment of their holiday.

\section{AUTHOR INFORMATION}

Kemakorn Chaiprasit is a lecturer of Management Department, Faculty of Business Administration, Chiang Mai University, Thailand. She received Ph.D. in Knowledge Management from Chiang Mai University, Thailand. Her interests are in the areas of knowledge management, learning organization, innovation, and SMEs competitiveness. She is currently doing her research in the area of happiness at work of employees in SMEs and evaluation of learning organization of SMEs.

Nittaya Jariengprasert is an Associate Professor of Management Department, Faculty of Business Administration, Chiang Mai University, Thailand. She received Ph.D. in Information Systems from Central Queensland University, Australia. Her interests are in the areas of information systems, E-commerce and social enterprises.

Apichart Chomphunut is a lecturer of Management Department, Faculty of Business Administration at Chiang Mai University, Thailand. He received his M.S. in Systems Science at Ottawa University, Canada. He has taught Business Statistics, Quantitative Analysis for Management, and Business Research courses for undergraduate and MBA program at Chiang Mai University. He has been conducted researches in various topics. His particular research topic interested is community business and SMEs.

Damrongsak Naparat is a lecturer of Management Department, Faculty of Business Administration, Chiang Mai University, Thailand. His expertise is in an area of information systems and information technology, nevertheless his previous research also includes developing knowledge base for sustainable tourism industry. He is currently pursuing his research degree in the area of sustainable social production at the University of New South Wales, Australia.

Jairat Jaturapataraporn is a small business counselor for E-commerce and a part-time lecturer of Marketing Department, Faculty of Business Administration, Chiang Mai University, Thailand. She received master degree in Arts of Philosophy. Her expertise is in an area of E-Commerce and website development.

\section{REFERENCES}

1. Castaneda, J.A., Frias, D.M., \& Rodriguez, M.A. (2007), "The influence of the internet on destination satisfaction", Internet Research, v. 17, n. 4, pp. 402-420

2. Eaimrittikrai, C. (2001). Marketing Publications Strategies on Internet for Event Organizing. Thesis for Master of Arts, Chulalongkorn University. Bangkok (Thailand).

3. E-Digital Research, (2009). Survey Content and user Experience in Online Travel [Online] http://www11.edigitalresearch.com/clients/full_survey.pdf (Accessed on 16 September 2009)

4. Henderson, D., Slaughter, L., \& Pegg, S. (2007). "Trust and New Technologies: Looking at Issues From the Perspective of the Young Tourist", The 2007 International Joint Conference on e-Commerce, eAdministration, e-Society, and e-Education, Hong Kong, August, 2007.

5. Kerdmongkol, K. (2003). Lifestyle, Information Seeking for Traveling and Travel Behavior of Working People. Thesis for Master of Law, Chulalongkorn University

6. Khumsri, P. (2006). Planning of Internet Marketing Strategy for Wing Travel Chiang Mai Co., Ltd. Independent Study for Master of Business Administration, Chiang Mai University 
7. Kunakornvaroj, K. (2001). Factors Affecting Trust towards Information Services Offered on the World Wide Web. Thesis for Master of Arts, Chulalongkorn University

8. Lai \& Fei Loi. (2007). National Strategic Positioning in E-Government Waves: A Case of e-Tourism in African Developing Countries. The 2007 International joint Conference on e-Commerce, e-Administration, e-Society, and e-Education, Hong Kong

9. Siripullop, K. (2006). Conference Paper to the $43^{\text {rd }}$ Anniversary of Marketing Association Thailand. Bangkok.

10. Social Research Institute, Chiang Mai University, (2004). Retained Value of the Tourism Industry of Thailand. Chiang Mai: Social Research Institute, Chiang Mai University

11. Tourism Authority of Thailand, (2008). Tourism Marketing Plan, Office of Information Technology, Tourism Authority of Thailand.

12. Werthner, H. \& Ricci, F. (2004), "E-Commerce and Tourism”. Communication of the ACM. 47 (12): 101 105 . 
NOTES 